\title{
Ecklonia cava Inhibits Glucose Absorption and Stimulates Insulin Secretion in Streptozotocin-Induced Diabetic Mice
}

\author{
Hye Kyung Kim \\ Department of Food and Biotechnology, Hanseo University, Seosan 356-706, Republic of Korea \\ Correspondence should be addressed to Hye Kyung Kim, hkkim111@dreamwiz.com \\ Received 29 December 2011; Accepted 20 February 2012 \\ Academic Editor: Mohamed Eddouks
}

Copyright () 2012 Hye Kyung Kim. This is an open access article distributed under the Creative Commons Attribution License, which permits unrestricted use, distribution, and reproduction in any medium, provided the original work is properly cited.

\begin{abstract}
Aims of study. Present study investigated the effect of Ecklonia cava (EC) on intestinal glucose uptake and insulin secretion. Materials and methods. Intestinal $\mathrm{Na}^{+}$-dependent glucose uptake (SGU) and $\mathrm{Na}^{+}$-dependent glucose transporter 1 (SGLT1) protein expression was determined using brush border membrane vesicles (BBMVs). Glucose-induced insulin secretion was examined in pancreatic $\beta$-islet cells. The antihyperglycemic effects of EC, SGU, and SGLT1 expression were determined in streptozotocin (STZ)induced diabetic mice. Results. Methanol extract of EC markedly inhibited intestinal SGU of BBMV with the $\mathrm{IC}_{50}$ value of $345 \mu \mathrm{g} / \mathrm{mL}$. SGLT1 protein expression was dose dependently down regulated with EC treatment. Furthermore, insulinotrophic effect of EC extract was observed at high glucose media in isolated pancreatic $\beta$-islet cells in vitro. We next conducted the antihyperglycemic effect of EC in STZ-diabetic mice. EC supplementation markedly suppressed SGU and SGLT1 abundance in BBMV from STZ mice. Furthermore, plasma insulin level was increased by EC treatment in diabetic mice. As a result, EC supplementation improved postprandial glucose regulation, assessed by oral glucose tolerance test, in diabetic mice. Conclusion. These results suggest that EC play a role in controlling dietary glucose absorption at the intestine and insulinotrophic action at the pancreas contributing blood glucose homeostasis in diabetic condition.
\end{abstract}

\section{Introduction}

Diabetes is one of the most prevalent and serious metabolic diseases worldwide. It is characterized by chronic hyperglycemia, impairment of insulin secretion from pancreatic $\beta$ cells, and insulin resistance in peripheral tissues. One of the therapeutic approaches for decreasing postprandial hyperglycemia is to retard the absorption of glucose by inhibition of carbohydrate-hydrolyzing enzymes such as $\alpha$-amylase and $\alpha$-glycosidase. However, they are not able to prevent glucose absorption when glucose itself has been ingested. Hence, the direct inhibition of intestinal glucose absorption could represent a novel mechanism for an antidiabetic drug.

Intestinal glucose absorption is thought to be regulated by the $\mathrm{Na}^{+}$-dependent glucose transporter 1 (SGLT1) at the apical membrane of the intestinal epithelia [1]. It has been shown in diabetic animals and humans that the capacity of the small intestine to absorb glucose increases at the brush border membrane vesicles (BBMVs) due to the enhanced activity and abundance of SGLT1 $[2,3]$.
In order to prevent or delay the progression of diabetes, insulin should be sufficiently secreted to compensate for insulin resistance in peripheral tissues. Thus, one of the mechanisms for the antidiabetic agents requires the characteristics of insulinotrophic action from pancreatic cells [4].

Marine algae have been identified as rich sources of structurally diverse bioactive compounds with great pharmaceuti$\mathrm{cal}$ and biomedical potential. The brown algae, Ecklonia cava (EC), are abundant in the south-west coastal region of Japan and Korea. It has been reported that EC extract has numerous biological activities including antioxidative, radical scavenging, immunomodulatory, and antimutagenic activities [5-8]. Recently, Lee et al. demonstrated that polyphenol isolated from EC inhibit $\alpha$-amylase and $\alpha$-glycosidase activities and alleviate postprandial hyperglycemia in streptozotocin(STZ-) induced diabetic mice [9]. However, the effect of EC on intestinal glucose uptake or insulinotrophic action has not been examined. In this study, we investigated the effects of EC on intestinal $\mathrm{Na}^{+}$-dependent glucose uptake, SGLT1 protein expression, and insulin secretion in pancreatic islets. 
Furthermore, the antihyperglycemic effects of EC in STZinduced diabetic mice were also evaluated.

\section{Materials and Methods}

2.1. Preparation of EC Powder and Extract. EC was obtained from a local market in Seosan, Republic of Korea. Fresh EC was washed, dried, and ground into powder. The EC powder was used for the in vivo experiment, and EC extract was used for the in vitro experiment. The dried powder was extracted three times with ten volumes of methanol at room temperature for 24 hour. The combined extracts were centrifuged, filtered, concentrated under vacuum, lyophilized, concentrated to $1 \mathrm{mg} / \mathrm{mL}$ with deionized water, and subsequently used for the experiment.

2.2. BBMV Isolation. BBMVs were prepared using a previously described method with some modification [10]. All subsequent isolation steps were performed at $4^{\circ} \mathrm{C}$. Male ICR mice (8-week old, Joongang Lab Animal Co., Korea) jejunal mucosal scrapings were suspended in $10 \mathrm{mM} \mathrm{HEPES/Tris}$ buffer (pH 7.5), containing $300 \mathrm{mM}$ mannitol and $300 \mathrm{mM}$ $\mathrm{MgCl}_{2}$, and homogenized in a glass-Teflon homogenizer (Glass-Col, Terre Haute, IN, USA) for $2 \mathrm{~min}$ at 3,000 rpm. The mixture was stirred for $2 \mathrm{~min}$ and centrifuged at $15,000 \mathrm{rpm}$ for $15 \mathrm{~min}$ at $4^{\circ} \mathrm{C}$. The supernatant was centrifuged at $30,000 \mathrm{rpm}$ for $45 \mathrm{~min}$. The resulting pellets were resuspended in $10 \mathrm{mM}$ HEPES/Tris buffer containing $300 \mathrm{mM}$ mannitol ( $\mathrm{pH} 7.5$ ) to a final protein concentration of $10 \mathrm{mg} / \mathrm{mL}$ and stored in liquid nitrogen until use. The degree of purity in BBMV was routinely assessed by the enrichment of alkaline phosphatase (ALP) in the finally prepared BBMV compared to the homogenate of intestinal scrapings. ALP activity was determined with ALP assay kit (Yeongdong Pharmaceutical Co., Seoul, Korea). The specific ALP activities of mucosal homogenate and BBMV suspension were $1.21 \pm 0.09$ and $6.21 \pm 0.48$ units/mg protein, respectively, exhibiting 5-fold enrichment in final BBMV fraction. The amount of protein in the BBMV was measured by the Bradford method [11].

2.3. $\mathrm{Na}^{+}$-Dependent Glucose Uptake. Measurement of $\mathrm{Na}^{+}$dependent glucose uptake by BBMV was determined by incubating $150 \mu \mathrm{L}$ BBMV suspension with $850 \mu \mathrm{L}$ uptake buffer containing $100 \mu \mathrm{M}$ 2-NBDG (Molecular Probes, Grand Island, NY, USA) and EC extract $(0.1 \mathrm{mg} / \mathrm{mL})$ at $37^{\circ} \mathrm{C}$ for $15 \mathrm{~min}$ in a shaking water bath. The uptake reaction was stopped by centrifuging for $20 \mathrm{~min}$ at $15,000 \mathrm{rpm}$, and the BBMV pellet was washed with stop buffer. The uptake and stop buffers were $10 \mathrm{mM}$ HEPES/Tris ( $\mathrm{pH} 7.5$ ) containing $150 \mathrm{mM} \mathrm{NaCl}$ and $300 u \mathrm{M}$ phlorizin (Sigma Co., St. Louis, USA), respectively. Glucose uptake was measured by detecting fluorescence intensity of 2-NBDG with a spectrofluorometer (excitation: $485 \mathrm{~nm}$, emission: $535 \mathrm{~nm}$ ). The difference between the glucose uptakes in the presence of $\mathrm{Na}^{+}$and phlorizin represents the $\mathrm{Na}^{+}$-dependent glucose uptake by SGLT1.
2.4. SGLT1 Expression. Glutaraldehyde was added to Immune well plate and incubated at $37^{\circ} \mathrm{C}$ for 1 hour. After washing the plate, an antigen of diluted BBMV membrane protein $(100 \mu \mathrm{L} /$ well $)$ and EC were added and incubated at $37^{\circ} \mathrm{C}$ for 2 hours. After washing the plate, the coated plates were blocked with blocking solution $(0.5 \%$ casein $)$ at $37^{\circ} \mathrm{C}$ for 1 hour. Primary antibody incubation was conducted with $100 \mu \mathrm{L}$ of the SGLTI polyclonal antibody (Chemicon International Inc., Temecula, CA, USA; diluted $1: 1000$ in $0.5 \%$ casein) at $37^{\circ} \mathrm{C}$ for 2 hour. Secondary antibody incubation was conducted with $100 \mu \mathrm{L}$ of the anti-rabbit IgG conjugated to horseradish peroxidase (diluted $1: 2000$ in $0.5 \%$ casein) at $37^{\circ} \mathrm{C}$ for 1 hour. For substrate incubation, $200 \mu \mathrm{L}$ of substrate solution (TMB $10 \mathrm{mg} / \mathrm{L}$ DMSO, $3 \% \mathrm{H}_{2} \mathrm{O}_{2}, 50 \mathrm{mM}$ sodium acetate buffer, $\mathrm{pH}$ 5.1) was added to each well and reacted for $15 \mathrm{~min}$. The enzymatic reaction was stopped by adding $50 \mu \mathrm{L}$ of $1 \mathrm{M} \mathrm{H}_{2} \mathrm{SO}_{4}$ to each well. The absorbance was determined at $450 \mathrm{~nm}$ using automated microplate reader (Model 550, BIO-RAD Laboratories, Philadelphia, PA, USA).

2.5. Insulin Secretion. Pancreatic islet cells were isolated from male mice by collagenase digestion [12]. Twenty islets were preincubated in Krebs-Ringer the bicarbonate (KRB) buffer, $\mathrm{pH} 7.4$, supplemented with serum albumin $(3 \mathrm{mg} / \mathrm{mL})$ and glucose $(3 \mathrm{mM})$ for $30 \mathrm{~min}$ at $37^{\circ} \mathrm{C}$ under humidified atmosphere of $5 \% \mathrm{CO}_{2}$. The islets were treated with EC extract $(50 \mu \mathrm{g} / \mathrm{mL})$ in 3,8 , and $16 \mathrm{mM}$ glucose KRB buffer for $60 \mathrm{~min}$ at $37^{\circ} \mathrm{C}$. Insulin concentration in each medium was determined using an ELISA procedure (Boehringer Mannheim Diagnostics, Germany).

2.6. Animal Study. Male ICR mice (8-week old) were housed in plastic cages under temperature- $\left(24 \pm 2{ }^{\circ} \mathrm{C}\right)$ and light(12-hour light/dark cycle) controlled conditions with constant humidity $(55 \pm 5 \%)$. The study has been carried out along the Korea National Institutes of Health Guidelines on the care and use of laboratory animals and approved by Hanseo University. The mice were randomly divided into four groups ( $n=10)$; normal control (NC), normal mice fed EC powder (NE), diabetic control (DC), and diabetic mice fed EC powder (DE). Normal and diabetic control mice were fed AIN-93-based semipurified standard diet, and experimental groups were supplemented with EC powder $(3 \%$, $\mathrm{w} / \mathrm{w})$. Diabetes was induced by a single intraperitoneal injection of STZ (Sigma, St. Louis, USA; $95 \mathrm{mg} / \mathrm{kg}$ in citrate buffer, $\mathrm{pH} 4.5$ ). NC group received the buffer only. Tail bleeds were performed 24 hour after injection, and animals with blood glucose concentrations above $300 \mathrm{mg} / \mathrm{dL}$ were considered to be diabetic and used in this study.

2.7. Oral Glucose Tolerance Test and Intestinal BBMV Glucose Uptake. At the end of 4 weeks of experimental period, mice were fasted overnight and administered with glucose $(1.5 \mathrm{~g} / \mathrm{kg})$. Blood samples were collected from the tail at various time points ( $0 \sim 90 \mathrm{~min})$ after glucose loading, and blood glucose levels were measured by one-touch basic glucose measurement system (Lifescan Inc., Milpitas, CA, USA). Mice were killed by decapitation immediately after 90-min 


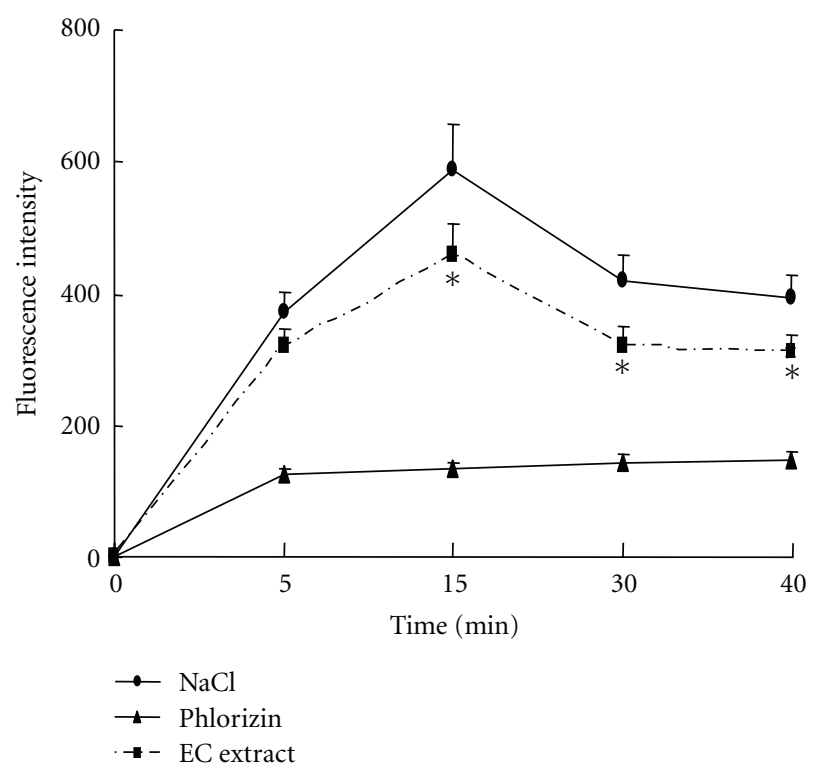

(a)

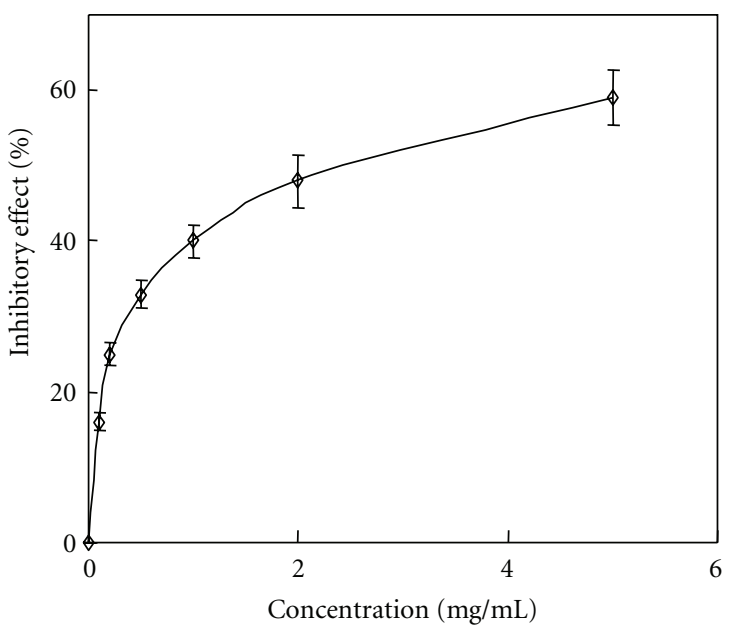

(b)

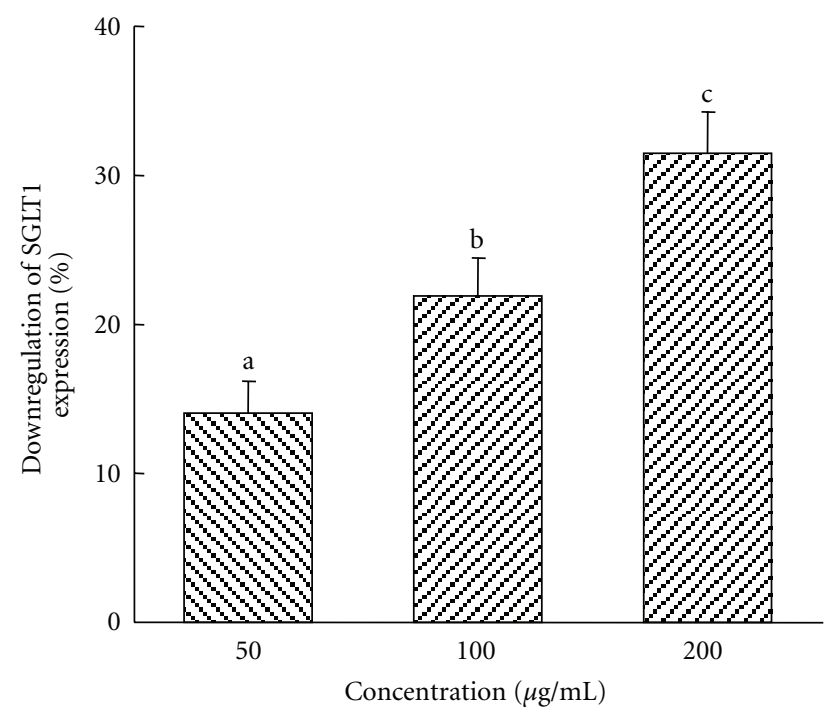

(c)

FIGURE 1: Effects of Ecklonia cava (EC) on $\mathrm{Na}^{+}$-dependent glucose uptake and SGLT1 expression. (a) Time course effects. *Effect of EC $(100 \mu \mathrm{g} / \mathrm{mL})$ at $P<0.05$. (b) Concentration-dependent inhibitory effects. Data are expressed as the \% of inhibitory activity compared to control group. Glucose uptake was measured with $150 \mathrm{mM} \mathrm{NaCl}$ or $300 \mu \mathrm{M}$ phlorizin to evaluate the sodium dependency of the glucose uptake. (c) Downregulation of SGLT1 expression by EC treatment. SGLT1 abundance was determined by ELISA analysis. ${ }^{\mathrm{a}-\mathrm{c}}$ Different letters are significantly different at $P<0.05$. Each value is the mean \pm SE of three different experiments.

blood samples were taken. Preparation of intestinal BBMV, $\mathrm{Na}^{+}$-dependent glucose uptake, and plasma insulin concentrations were determined as described above.

2.8. Statistical Analysis. Results were presented as mean $\pm \mathrm{SE}$, and significant differences $(P<0.05)$ between groups were analyzed by ANOVA followed by Tukey's post hoc test. The $50 \%$ inhibitory concentration $\left(\mathrm{IC}_{50}\right)$ value was calculated using Prism program (GraphPad Software Inc., La Jolla, CA, USA).

\section{Results}

3.1. $\mathrm{Na}^{+}$-Dependent Glucose Uptake and SGLT1 Expression in $B B M V$. The intestinal glucose uptake inhibitory activity of EC extract was determined by in vitro model of BBMV using 2-NBDG. $\mathrm{Na}^{+}$-dependent 2-NBDG uptake by normal mice intestinal BBMV was time- and concentration-dependent and almost linear up to $15 \mathrm{~min}$ and $200 \mu \mathrm{g} / \mathrm{mL}$ (Figures 1(a) and 1(b)). The uptake of 2-NBDG into the intestinal BBMV showed a typical overshoot reaching its peak at 15 min (Figure 1(a)). The overshoot was not observed in 


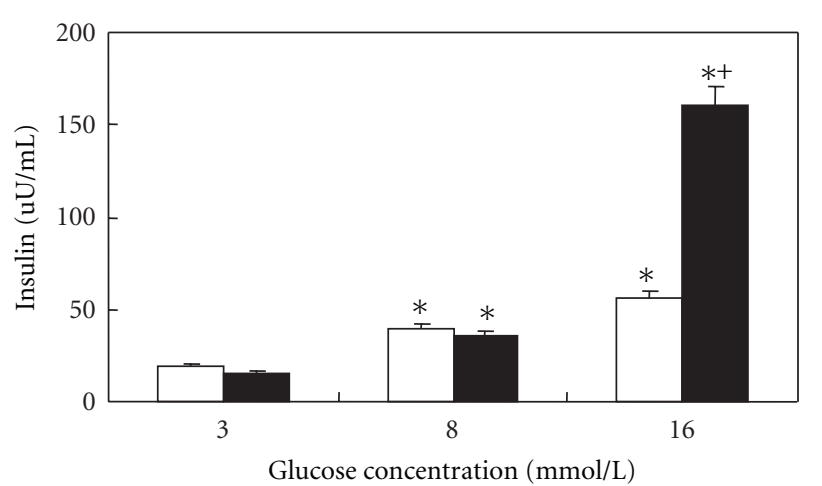

$\square$ Control
$\square$ EC

FIGURE 2: Glucose-stimulated insulin secretion in pancreatic islet cells. The incubations were performed with or without EC extract $(50 \mu \mathrm{g} / \mathrm{mL})$ in 3,8 , or $16 \mathrm{mM}$ glucose media. ${ }^{*}$ Significant effect of media glucose concentration and ${ }^{+}$significant effect of EC treatment at $P<0.05$.

the presence of phlorizin, a SGLT1 inhibitor. These results suggest that intestinal glucose uptake mediated by SGLT1 actively occurs after glucose ingestion reaching its peak shortly, and SGLT1 inhibitor abolished the active uptake after glucose ingestion. Furthermore, in the presence of phlorizin, glucose uptake was very low showing about $22 \%$ of the total glucose uptake at $15 \mathrm{~min}$ indicating that BBMV used SGLT1 as a major mechanism for glucose uptake. EC extract at $100 \mu \mathrm{g} / \mathrm{mL}$ significantly suppressed the $\mathrm{Na}^{+}$-dependent glucose uptake into the BBMV in the entire uptake profile (Figure 1(a)). The inhibitory effects were 14, 22, 24, and 22\% at $5,15,30$, and 40 min incubation, respectively. The $\mathrm{Na}^{+}-$ dependent glucose uptake inhibitory activity of BBMV with various concentrations of EC extract exhibited a dose dependency with $\mathrm{IC}_{50}$ at $345 \pm 54 \mu \mathrm{g} / \mathrm{mL}$ (Figure 1(b)).

The abundance of SGLT1, measured by ELISA analysis, was downregulated in a dose-dependent manner and showed $31.4 \%$ reduction with $200 \mu \mathrm{g} / \mathrm{mL}$ EC treatment (Figure 1(c)).

3.2. Glucose-Induced Insulin Secretion in $\beta$-Islet Cells. Figure 2 shows the stimulatory effect of the EC extract on insulin secretion in the presence of glucose $(3 \sim 16 \mathrm{mM})$. Glucose induced a dose-dependent increase of insulin secretion from pancreatic $\beta$-islet cells in both control and EC-treated group. In the presence of $16 \mathrm{mM}$ glucose, insulin secretion increased by 2.9- and 10.4-fold compared to the $3 \mathrm{mM}$ glucose media in control and EC-treated group, respectively. EC extract fails to stimulate insulin output in $3 \sim 8 \mathrm{mM}$ glucose media. However, EC extract significantly boosted insulin secretion in $16 \mathrm{mM}$ glucose media exhibiting 2.8 -fold increase as compared with control group.

3.3. Intestinal Glucose Uptake in Diabetic Mice. To validate the in vitro results, the antihyperglycemic effects of EC supplementation were investigated in STZ-induced diabetic mice. Induction of diabetes caused significant weight loss

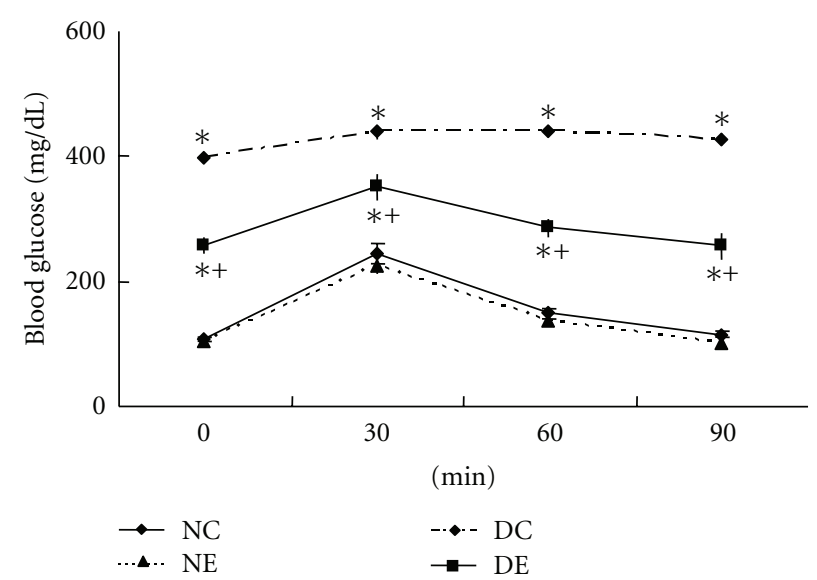

FIGURE 3: Effect of Ecklonia cava (EC) on oral glucose tolerance. Glucose $(1.5 \mathrm{~g} / \mathrm{kg})$ was administrated at time zero after 12 hour fasting. Normal control mice (NC); normal mice supplemented with EC powder for 4 weeks (NE); STZ-diabetic control mice (DC); diabetic mice supplemented with EC powder (DE). Values are mean \pm SE of 10 mice in each group. * Significantly different from normal mice and ${ }^{+}$significant effect of EC treatment at $P<0.05$.

resulting in negative body weight gain, whereas EC consumption for 4 weeks ameliorated weight loss (Table 1). The $\mathrm{Na}^{+}$-dependent glucose uptake by BBMV prepared from diabetic mice was increased by $39.7 \%$ compared with normal mice, and EC supplementation reduced the $\mathrm{Na}^{+}$-dependent glucose uptake to near normal value. In normal mice, EC supplementation slightly (14.8\%) reduced the $\mathrm{Na}^{+}$-dependent glucose uptake without statistical significance. SGLT1 expression in BBMV was 2.6-fold increased in diabetic mice compared to normal mice. Consumption of EC reduced the SGLT1 protein expressions by $17 \%$ and $34 \%$ in normal and diabetic mice, respectively, confirming the in vitro results. The fasting blood glucose concentrations were markedly decreased by EC supplementation in diabetic mice without any significant differences in normal mice. Plasma insulin concentrations were markedly reduced in diabetic mice, and EC supplementation significantly increased the plasma insulin level reaching $75 \%$ of the normal insulin level. However, EC supplementation did not affect the plasma insulin concentrations in normal mice.

The oral glucose tolerance test (OGTT) can be used to evaluate blood glucose homeostasis and also indirectly evaluate glucose absorption. As shown in Figure 3, glucose load in normal mice produced rapid increase in blood glucose levels from $108 \pm 4$ to $245 \pm 15 \mathrm{mg} / \mathrm{dL}$ at $30 \mathrm{~min}$ and returned to baseline values within $90 \mathrm{~min}$. In contrast, STZ-induced diabetic mice demonstrated basal hyperglycemia (399 \pm $14 \mathrm{mg} / \mathrm{dL}$ ) which remained above $400 \mathrm{mg} / \mathrm{dL}$ during all time points determined. The peak increase in serum glucose concentrations in diabetic mice was observed after $60 \mathrm{~min}$ of glucose treatment, while that of normal mice observed after $30 \mathrm{~min}$, indicating delayed glucose homeostasis in diabetic mice. Consumption of EC powder slightly reduced fasting blood glucose level in normal mice without any statistical significance. However, EC supplementation in diabetic mice 
TABLE 1: Effect of Ecklonia cava (EC) on blood glucose regulation.

\begin{tabular}{lcccc}
\hline & NC & NE & DC & DE \\
\hline Body weight gain $(g)$ & $7.8 \pm 0.9^{\mathrm{a}}$ & $8.4 \pm 0.6^{\mathrm{a}}$ & $-5.9 \pm 0.7^{\mathrm{b}}$ & $-2.1 \pm 0.4^{\mathrm{c}}$ \\
Glucose uptake $^{1}$ & $357 \pm 28^{\mathrm{a}}$ & $304 \pm 17^{\mathrm{a}}$ & $499 \pm 33^{\mathrm{b}}$ & $392 \pm 22^{\mathrm{a}, \mathrm{c}}$ \\
SGLT1 expression & $1.00 \pm 0.21^{\mathrm{a}}$ & $0.83 \pm 0.22^{\mathrm{a}}$ & $2.61 \pm 0.34^{\mathrm{b}}$ & $1.72 \pm 0.20^{\mathrm{c}}$ \\
Blood glucose $(\mathrm{mg} / \mathrm{dL})$ & $112 \pm 10^{\mathrm{a}}$ & $109 \pm 1^{\mathrm{a}}$ & $395 \pm 13^{\mathrm{b}}$ & $240 \pm 19^{\mathrm{c}}$ \\
Plasma insulin $(\mathrm{ng} / \mathrm{mL})$ & $1.28 \pm 0.03^{\mathrm{a}}$ & $1.25 \pm 0.03^{\mathrm{a}}$ & $0.50 \pm 0.01^{\mathrm{b}}$ & $0.96 \pm 0.03^{\mathrm{c}}$ \\
\hline
\end{tabular}

Values are means \pm SE of 10 mice in each group. NC: normal control mice; NE: normal mice supplied with EC powder (3\%). DC: STZ-mice; DE: STZ-mice supplied with EC. ${ }^{1} \mathrm{Na}^{+}$-dependent glucose uptake by BBMV was expressed as fluorescence intensity. ${ }^{2}$ Relative SGLT1 protein expression.

${ }^{a-c}$ Different superscript letter means significantly different at $P<0.05$.

dramatically decreased fasting blood glucose level, and postprandial glucose tolerance showed definite improvement exhibiting similar pattern as normal mice with peak increase at 30 min.

\section{Discussion}

The importance of postprandial glucose control in the development of diabetic complications is widely recognized based on many epidemiological studies. Several inhibitors of $\alpha$-amylase or $\beta$-glucosidase were proposed to control postprandial hyperglycemia, but the inhibitors of these enzymes are not able to prevent glucose absorption when glucose itself has been ingested. Hence, it might be important to inhibit intestinal glucose absorption as well as glucosidase or amylase activity for the regulation of postprandial blood glucose level.

The capacity of the small intestine to absorb glucose increases in patients with type 2 diabetes and in experimentally induced diabetic animals as a consequence of the enhanced activity and abundance of SGLT1 $[2,3]$ suggesting SGLT1 as a potential target of drug development for glycemic control in diabetic patients.

In the present study, we conducted an in vitro study to examine the effects of $\mathrm{EC}$ on intestinal glucose uptake using BBMV. The results revealed that EC reduced SGLT1 activity, assessed by $\mathrm{Na}^{+}$-dependent glucose uptake and SGLT1 protein expression in BBMV. Furthermore, the insulinotrophic effect of EC extract was observed at high glucose $(16 \mathrm{mM})$ environment. Compared to the results at $3 \mathrm{mM}$ media glucose, insulin secretion at $16 \mathrm{mM}$ glucose with EC extract increased by 10.4-fold. This is consistent with the observation that glucose acts synergistically with antidiabetic plant to promote insulin secretion [13]. The elevated insulin secretion with EC treatment at high glucose environment agrees with in vivo results in Table 1, thus strengthening the evidence that the EC acts as a stimulator of insulin secretion. Diabetic mice (blood glucose $>20 \mathrm{mM}$ ) markedly increased plasma insulin concentration by $192 \%$ while $\mathrm{Na}^{+}$-dependent glucose uptake was reduced by $22 \%$ in response to EC supplementation. These results suggest that the relative contribution of increased islet cell insulin secretion is more potent than reduced intestinal $\mathrm{Na}^{+}$-dependent glucose uptake for the regulation of blood glucose level in EC-supplemented diabetic mice. Therefore, it is significant that the EC extract could potentiate insulin secretion at higher glucose concentration, which could be useful in situations where chronic hyperglycemia decreases the sensitivity of $\beta$-islet cells to glucose-induced insulin secretion [14].

We subsequently examined the in vivo effect of EC on glucose uptake by BBMV prepared from STZ-diabetic mice fed EC diet. Recent studies have shown that modifications of systemic glycemia in OGTT reflect the activity of the intestinal glucose transporter SGLT1 [15]. STZ-induced diabetic mice exhibited severe hyperglycemia with increased $\mathrm{Na}^{+}$dependent glucose uptake activity and SGLT1 expression in intestinal BBMV compared with normal mice. EC consumption reduced intestinal $\mathrm{Na}^{+}$-dependent glucose uptake and SGLT1 expression in diabetic mice resulting in improvement of OGTT and blood glucose level. The blood glucose and insulin levels in EC supplemented mice were not completely normalized whereas the intestinal $\mathrm{Na}^{+}$-dependent glucose uptake was normalized, again suggesting the importance of pancreatic insulin secretion for the regulation of blood glucose homeostasis. The enhancement of intestinal glucose uptake in diabetic mice might be attributed to several factors, such as an increase in mucosal mass, an increase in the turnover of the transporter, and/or an increase in the number of SGLT1. It has been reported that glucose transporter levels including SGLT1 are elevated in diabetic animals and humans $[2,3]$.

Administration of EC suppressed the body weight loss in diabetic mice suggesting that EC treatment may beneficially affect the metabolic state in diabetes. Indeed, it has been reported that administration of phlorizin or T-1095, $\mathrm{Na}^{+}$-dependent glucose transporter inhibitor, leads to a body weight gain in STZ diabetic rats $[16,17]$.

Seaweeds contain appreciable amounts of polyphenols, and Ahn et al. [18] reported that the content of polyphenols in EC is about $18.3 \%$. It has been suggested that polyphenols modulate hyperglycemia through various mechanisms. First, glucose absorption from intestine was reduced by inhibiting $\alpha$-glucosidase and/or SGLT1 activity. Catechin [19], flavonoid [20], and quercetin [21] have been reported to inhibit $\alpha$-glucosidase activity via steric hindrance. The influence of polyphenols on glucose transporters has been studied in vitro by using intestinal BBMV or everted sacs and Caco- 2 cells. The $\mathrm{Na}^{+}$-dependent SGLT1-mediated glucose transport was inhibited by tea catechins [22, 23], tannic acids [24], and quercetin monoglucosides [25]. Kobayashi et al. [22] and Shimizu et al. [23] reported that green tea polyphenols, 
especially epicatechin gallate (ECg), inhibit SGLT1 in a competitive manner interacting as antagonist-like molecules, although ECg itself was not transported via the glucose transporters. Oliveira et al. reported that polyphenol-rich Yerba maté decreased intestinal SGLT1 expression in alloxan-induced diabetic rats [26]. Second, polyphenols increase pancreatic insulin secretion. Soy isoflavonoids (genistein and daidzein) preserved insulin production by the $\beta$-cells in STZinduced diabetic mice [27]. EGCG activates IRS2 and AMPK signalling in rat pancreatic $\beta$-cells [28]. Genistein augments cAMP accumulation and insulin release in MIN6 cells [29]. Therefore, it is obvious that the pancreas is one of the targets of dietary polyphenol bioactivity although no single mechanism has been identified to be responsible for the response. Although the identity of chemical component responsible for the antidiabetic action of EC in present study is unknown, it would be of considerable interest to further elucidate the mechanism and component(s) underlying the action of EC.

In conclusion, this study demonstrates that EC manifests two important antidiabetic properties: the inhibition of intestinal $\mathrm{Na}^{+}$-dependent glucose absorption mediated by reduced expression of SGLT1 and the stimulation of insulin secretion in hyperglycemic environment, resulting in improvement of the glucose regulation in diabetic condition. The present findings identify, for the first time to our knowledge, the inhibitory effect on intestinal glucose uptake and insulinotrophic effect of EC.

\section{Abbreviations}

EC: Ecklonia cava

SGU: $\quad \mathrm{Na}^{+}$-dependent glucose uptake

SGLT1: $\mathrm{Na}^{+}$-dependent glucose transporter 1

BBMV: Brush border membrane vesicles

STZ: Streptozotocin

ALP: Alkaline phosphatase.

\section{Conflict of Interests}

The authors declare no conflict of interests.

\section{Acknowledgment}

This work was supported by a grant from the 2010 Fundamental R\&D Program of Hanseo University.

\section{References}

[1] M. A. Hediger and D. B. Rhoads, "Molecular physiology of sodium-glucose cotransporters," Physiological Reviews, vol. 74, no. 4, pp. 993-1026, 1994.

[2] R. N. Fedorak, C. I. Cheeseman, A. B. R. Thomson, and V. M. Porter, "Altered glucose carrier expression: mechanism of intestinal adaptation during streptozocin-induced diabetes in rats," American Journal of Physiology, vol. 261, no. 4, pp. G585G591, 1991.
[3] J. Dyer, I. S. Wood, A. Palejwala, A. Ellis, and S. P. ShiraziBeechey, "Expression of monosaccharide transporters in intestine of diabetic humans," American Journal of Physiology, vol. 282, no. 2, pp. G241-G248, 2002.

[4] G. Perseghin, A. Caumo, C. Arcelloni et al., "Contribution of abnormal insulin secretion and insulin resistance to the pathogenesis of type 2 diabetes in myotonic dystrophy," Diabetes Care, vol. 26, no. 7, pp. 2112-2118, 2003.

[5] H. C. Shin, H. J. Hwang, K. J. Kang, and B. H. Lee, "An antioxidative and antiinflammatory agent for potential treatment of osteoarthritis from Ecklonia cava," Archives of Pharmacal Research, vol. 29, no. 2, pp. 165-171, 2006.

[6] Y. Athukorala, K. N. Kim, and Y. J. Jeon, "Antiproliferative and antioxidant properties of an enzymatic hydrolysate from brown alga, Ecklonia cava," Food and Chemical Toxicology, vol. 44, no. 7, pp. 1065-1074, 2006.

[7] G. Ahn, I. Hwang, E. Park et al., "Immunomodulatory effects of an enzymatic extract from Ecklonia cava on murine splenocytes," Marine Biotechnology, vol. 10, no. 3, pp. 278-289, 2008.

[8] S. H. Lee, J. S. Han, S. J. Heo, J. Y. Hwang, and Y. J. Jeon, "Protective effects of dieckol isolated from Ecklonia cava against high glucose-induced oxidative stress in human umbilical vein endothelial cells," Toxicology in Vitro, vol. 24, no. 2, pp. 375$381,2010$.

[9] S. H. Lee, M. H. Park, S. J. Heo et al., "Dieckol isolated from Ecklonia cava inhibits $\alpha$-glucosidase and $\alpha$-amylase in vitro and alleviates postprandial hyperglycemia in streptozotocininduced diabetic mice," Food and Chemical Toxicology, vol. 48, no. 10, pp. 2633-2637, 2010.

[10] E. S. Debnam and P. A. Sharp, "Acute and chronic effects of pancreatic glucagon on sugar transport across the brush-border and basolateral membranes of rat jejunal enterocytes," Experimental Physiology, vol. 78, no. 2, pp. 197-207, 1993.

[11] M. M. Bradford, "A rapid and sensitive method for the quantitation of microgram quantities of protein utilizing the principle of protein dye binding," Analytical Biochemistry, vol. 72, no. 1-2, pp. 248-254, 1976.

[12] P. E. Lacy and M. Kostianovsky, "Method for the isolation of intact islets of Langerhans from the rat pancreas," Diabetes, vol. 16, no. 1, pp. 35-39, 1967.

[13] K. A. Asamoah, D. A. Robb, and B. L. Furman, "Chronic chloroquine treatment enhances insulin release in rats," Diabetes Research and Clinical Practice, vol. 9, no. 3, pp. 273-278, 1990.

[14] J. L. Leahy, S. Bonner-Weir, and G. C. Weir, “ $\beta$-cell dysfunction induced by chronic hyperglycemia: current ideas on mechanism of impaired glucose-induced insulin secretion," Diabetes Care, vol. 15, no. 3, pp. 442-455, 1992.

[15] R. Ducroc, T. Voisin, A. El Firar, and M. Laburthe, "Orexins control intestinal glucose transport by distinct neuronal, endocrine, and direct epithelial pathways," Diabetes, vol. 56, no. 10, pp. 2494-2500, 2007.

[16] S. M. Brichard, J. C. Henquin, and J. Girard, "Phlorizin treatment of diabetic rats partially reverses the abnormal expression of genes involved in hepatic glucose metabolism," Diabetologia, vol. 36, no. 4, pp. 292-298, 1993.

[17] T. Adachi, K. Yasuda, Y. Okamoto et al., "T-1095, A renal $\mathrm{Na}^{+}$-glucose transporter inhibitor, improves hyperglycemia in streptozotocin-induced diabetic rats," Metabolism, vol. 49, no. 8, pp. 990-995, 2000.

[18] G. Ahn, E. Park, W. W. Lee et al., "Enzymatic extract from Ecklonia cava induces the activation of lymphocytes by IL-2 production through the classical NF- $\kappa \mathrm{B}$ pathway," Marine Biotechnology, vol. 13, no. 1, pp. 66-73, 2011. 
[19] T. Matsui, T. Tanaka, S. Tamura et al., " $\alpha$-glucosidase inhibitory profile of catechins and theaflavins," Journal of Agricultural and Food Chemistry, vol. 55, no. 1, pp. 99-105, 2007.

[20] K. Johnston, P. Sharp, M. Clifford, and L. Morgan, "Dietary polyphenols decrease glucose uptake by human intestinal Caco-2 cells," FEBS Letters, vol. 579, no. 7, pp. 1653-1657, 2005.

[21] K. Tadera, Y. Minami, K. Takamatsu, and T. Matsuoka, "Inhibition of $\alpha$-glucosidase and $\alpha$-amylase by flavonoids," Journal of Nutritional Science and Vitaminology, vol. 52, no. 2, pp. 149-153, 2006.

[22] Y. Kobayashi, M. Suzuki, H. Satsu et al., "Green tea polyphenols inhibit the sodium-dependent glucose transporter of intestinal epithelial cells by a competitive mechanism," Journal of Agricultural and Food Chemistry, vol. 48, no. 11, pp. 56185623, 2000.

[23] M. Shimizu, Y. Kobayashi, M. Suzuki, H. Satsu, and Y. Miyamoto, "Regulation of intestinal glucose transport by tea catechins," BioFactors, vol. 13, no. 1-4, pp. 61-65, 2000.

[24] C. A. Welsch, P. A. Lachance, and B. P. Wasserman, "Dietary phenolic compounds: inhibition of $\mathrm{Na}^{+}$-dependent D-glucose uptake in rat intestinal brush border membrane vesicles," Journal of Nutrition, vol. 119, no. 11, pp. 1698-1704, 1989.

[25] R. Cermak, S. Landgraf, and S. Wolffram, "Quercetin glucosides inhibit glucose uptake into brush-border-membrane vesicles of porcine jejunum," British Journal of Nutrition, vol. 91, no. 6, pp. 849-855, 2004.

[26] D. M. Oliveira, H. S. Freitas, M. F. F. Souza et al., "Yerba Maté (Ilex paraguariensis) aqueous extract decreases intestinal SGLT1 gene expression but does not affect other biochemical parameters in alloxan-diabetic wistar rats," Journal of Agricultural and Food Chemistry, vol. 56, no. 22, pp. 10527-10532, 2008.

[27] M. P. Lu, R. Wang, X. Song et al., "Dietary soy isoflavones increase insulin secretion and prevent the development of diabetic cataracts in streptozotocin-induced diabetic rats," Nutrition Research, vol. 28, no. 7, pp. 464-471, 2008.

[28] E. P. Cai and J. K. Lin, "Epigallocatechin gallate (EGCG) and rutin suppress the glucotoxicity through activating IRS2 and AMPK signaling in rat pancreatic beta cells," Journal of Agricultural and Food Chemistry, vol. 57, no. 20, pp. 9817-9827, 2009.

[29] T. Ohno, N. Kato, C. Ishii et al., "Genistein augments cyclic adenosine $3^{\prime} 5^{\prime}$-monophosphate (cAMP) accumulation and insulin release in MIN6 cells," Endocrine Research, vol. 19, no. 4, pp. 273-285, 1993. 


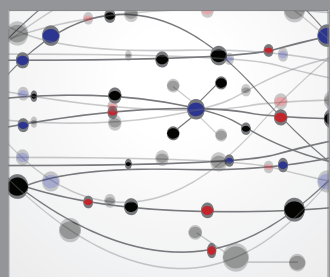

The Scientific World Journal
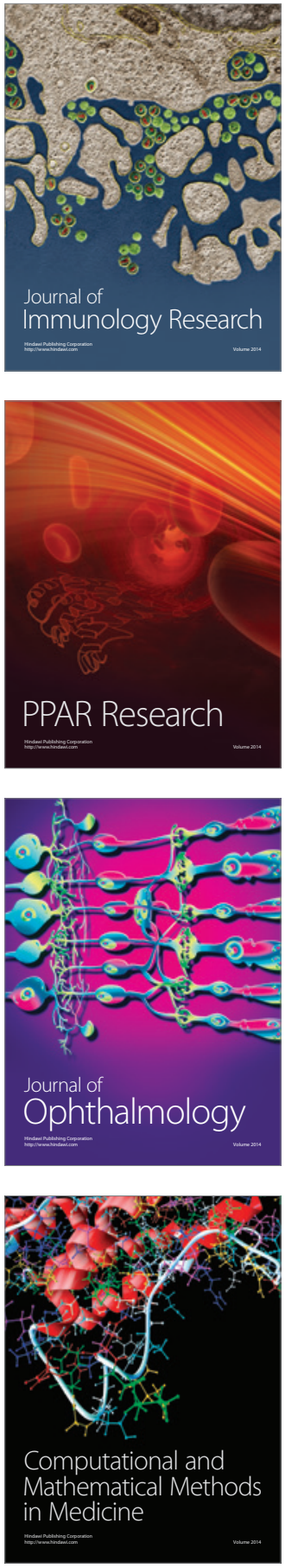

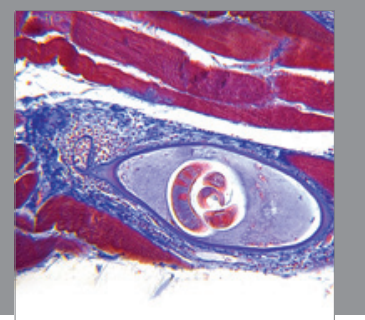

Gastroenterology

Research and Practice
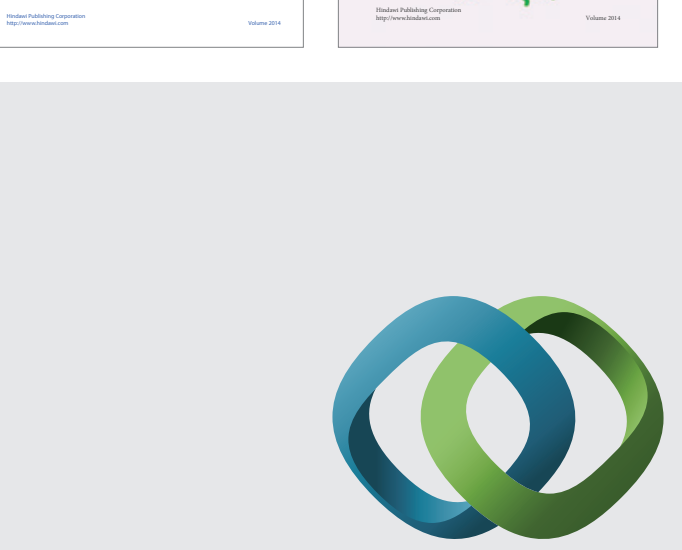

\section{Hindawi}

Submit your manuscripts at

http://www.hindawi.com
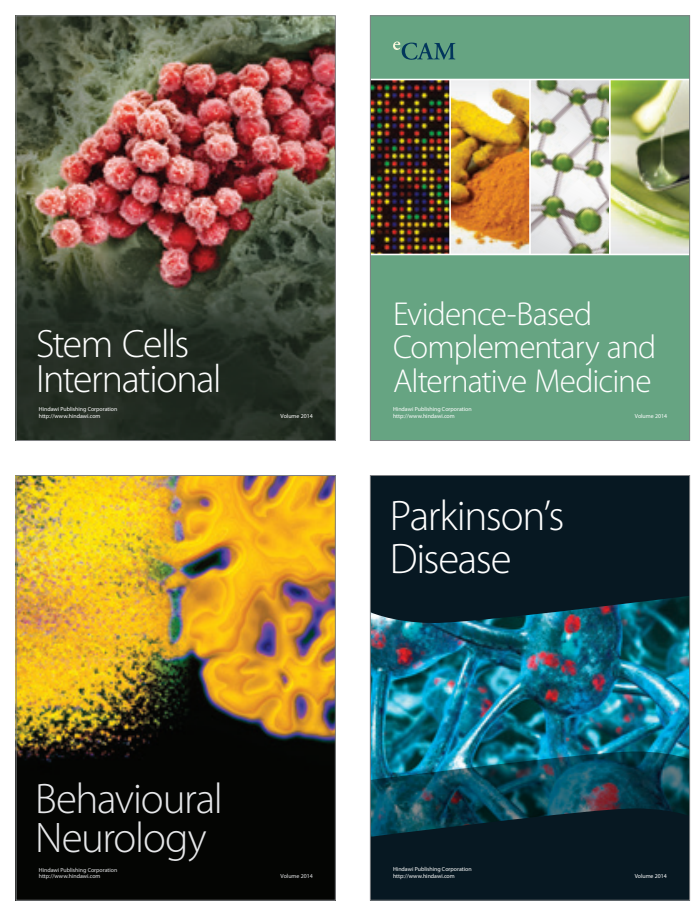

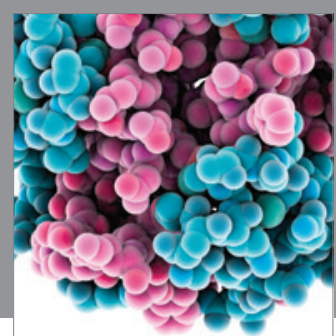

Journal of
Diabetes Research

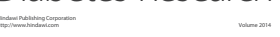

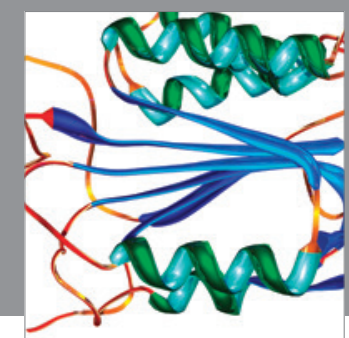

Disease Markers
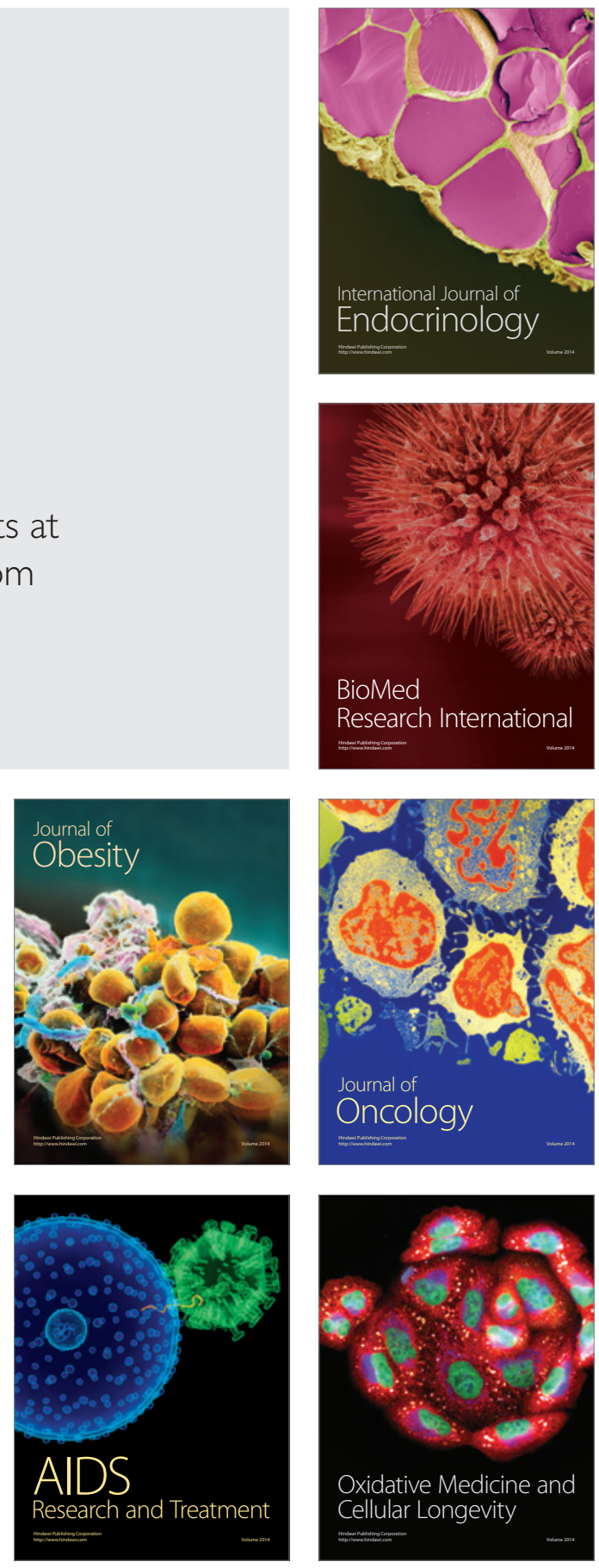